American Journal of Pharmaceutical Education 2018; 82 (6) Article 6280.

\title{
RESEARCH
}

\section{Evaluating the Effectiveness of a Focused Debate on the Development of Ethical Reasoning Skills in Pharmacy Technician Students}

\author{
Seána Hogan, MPSI, EdD, Julie Dunne, PhD \\ College of Sciences and Health, Dublin Institute of Technology, Dublin, Ireland \\ Submitted January 17, 2017; accepted May 9, 2017; published August 2018.
}

Objective. To evaluate the effectiveness of debating an ethical dilemma on the development of ethical reasoning skills in pharmacy technician students.

Methods. A mixture of qualitative and quantitative methods was used. This included analysis of before and after 5-minute papers, a sentiment survey, thematic analysis of student reflective writing and a qualitative questionnaire by an independent observer.

Results. Twenty-five students participated in the study. The 5-minute papers showed improvement in student learning. In the sentiment survey, $83 \%$ of students agreed or strongly agreed that they had a better understanding of ethical dilemmas following the debate. The main theme identified from student blogs was the variety of different opinions expressed during the debate.

Conclusion. Debating was an effective means of exploring ethics with pharmacy technician students.

Keywords: ethical debates, pharmacy practice, pharmacy technicians, curriculum development

\section{INTRODUCTION}

Evaluating a new education activity to develop students' understanding of ethical dilemmas and the choices they make was the main aim of this study. Debates are often reported in the literature as an effective way to explore ethics. ${ }^{1-3}$ Understanding the professional environment of pharmacy helps explain why ethics for pharmacy technicians is an emerging area to be developed. The Pharmacy Act was introduced in Ireland in 2007 signalling a new era for Irish pharmacy. ${ }^{4}$ The Act was a major development that overhauled the regulation of pharmacy and set new standards of governance, fitness to practice, and registration of pharmacies and pharmacists. However, the Act did not address difficulties faced by pharmacy technicians such as varying entry level qualifications, the need for professional development, and regulation and registration issues. ${ }^{5}$ Simultaneously, pharmacists were developing their role in the delivery of patient-centered services, which was affecting the role of pharmacy technicians and raising implications for their professional education and training. Pharmacy technicians in Ireland have two routes to qualification: a full-time, college-based course and a work-based-only course delivered in a modular format by distance learning. Neither of these routes leads

Corresponding Author: Seána Hogan, College of Sciences and Health, Dublin Institute of Technology, Cathal Brugha St., Dublin 2, Ireland. Tel: 00353877731073. E-mail: seana. hogan@dit.ie to registration. The issues of regulation and registration of pharmacy technicians as a profession have not been exclusive to Ireland; internationally, there has been much debate and discussion. ${ }^{6-10}$ Discussion of professionalization brings the issue of ethics to the forefront. Ethics is defined as "moral principles that govern a person's behaviour or the conducting of an activity." "Health care ethics education has become a basic requirement for any health profession training program, and should span the continuum of undergraduate, postgraduate, and continuing education. ${ }^{12}$ One of the standards listed in the Accreditation Council for Pharmacy Education's (ACPE) Standards for Pharmacy Technician Education and Training Programs addresses technicians' abilities to demonstrate ethical conduct in all job-related activities. ${ }^{7}$ Ethical responsibilities are formally expanding throughout health care with nursing staff and allied health professionals producing their own ethical guidelines. ${ }^{13}$ According to the International Pharmaceutical Federation (FIP), codes of ethics should be developed across health care professions. ${ }^{14}$ FIP recommends that institutions offering pharmacy education and continuing professional development (CPD) should include the Code of Ethics and its underlying principles of respect for the autonomy of persons, beneficence, non-maleficence and justice, in their offerings for all students and professionals. ${ }^{15}$

Codes of ethics have been developed for pharmacy technicians in other countries. For example, both the American Association of Pharmacy Technicians (AAPT) 


\section{American Journal of Pharmaceutical Education 2018; 82 (6) Article 6280.}

and the General Pharmaceutical Council of Great Britain (GPhC) have developed core competencies that incorporate ethical dimensions that are used to illustrate and guide expected behaviours of technicians in both training and practice. $^{16-20}$

In Canada, pharmacy technicians are required to practice within legal requirements, demonstrate professionalism and uphold professional standards of practice, codes of ethics and policies, and apply ethical principles in the decision-making process. ${ }^{20}$ In Great Britain, technicians must follow the standards of conduct, ethics and performance as dictated by the GPhC. Every registered pharmacy technician is responsible for their own actions. ${ }^{17}$ In the US, ethical principles apply to technicians working in all settings, are based on the application and support of the moral obligations that guide the pharmacy profession in relationships with patients, other health care professionals, and society. ${ }^{16}$ In light of these requirements, it is incumbent upon pharmacy technician educators to incorporate ethical development into their educational programs.

Considering the role of pharmacy technician training programs in relation to the professional formation of technicians, the issue of ethics was identified as an area for development. Hindmarch and colleagues reviewed various methods of teaching ethics, including the role of undergraduate peer-based health care ethics teaching. ${ }^{13}$ Their study appraised interventions in which peers play a significant role in the development of fellow students and included peer discussions that were guided by clinical faculty members trained in ethics facilitation. ${ }^{13}$ Their findings suggest peer-based ethics education is an effective and valued educational methodology in training health care professionals. ${ }^{13}$ Numerous ways for incorporating ethics lessons into courses have been reported, and include regular class discussions, dedicated lectures, shared personal reflections, reading assignments, paper assignments, case study ethics presentations and debates. ${ }^{21}$

In-class debates involve peer-learning and can provide an excellent opportunity for active learning and may also support oral communication skills and critical thinking in students. ${ }^{22}$ Lampkin and colleagues found that a debate series in a first-year pharmacy self-care course was useful as an active-learning classroom tool to use in conjunction with didactic instruction to improve overall education. ${ }^{23}$ A study by Randolph found that survey results of student perceptions of the use of debates as a teaching strategy in the allied health professions showed that debates encouraged active student participation in class and outside-of-class research experiences, provided students an opportunity to discuss issues and develop conclusions, and promoted the ability for students to advocate for themselves. ${ }^{24}$ Reubin and colleagues reported that debates can be used as an adjunct educational methodology that complements other course content. ${ }^{25}$ Hannah and colleagues also found that debates offer a useful strategy for teaching ethics in pharmacy courses. ${ }^{3}$

The aim of this study was to evaluate the implementation of a cross-curricular intervention in the form of a debate on an ethical dilemma to integrate ethics into pharmacy technician professional formation and investigate if establishing such an intervention would improve student ethical reasoning skills. Literature focusing on pharmacy technician education is limited and this study attempts to redress this issue. A shared assignment to integrate pharmaceutics and pharmacy practice course concepts was used as a guide in the development of this curriculum intervention. ${ }^{26}$

\section{METHODS}

After a preliminary pilot investigative cycle in 20142015 indicated a positive outcome through an informal discussion with the class, a more robust mixed methods approach including both qualitative and quantitative methods was used in this study. Qualitative methods used included reflective writing pieces on the exercise or blogs recorded in the students' electronic portfolios, a survey for students to express their view and opinions on the exercise, and a questionnaire for an international visiting lecturer who was observing the activity. Qualitative data included students' ePortfolio reports, the visiting lecturer's questionnaire, and section 2 of the students' sentiment survey. Quantitative methods included $t$-test analysis of pre- and post-5-minute papers and section 1 of the sentiment survey. This broad mixed method approach allowed for triangulation of findings and addressed issues of validity. Twenty-five second-year pharmacy technician students in a two-year program participated in this study. The study participants included male students, female students, mature students, access or non-traditional students, and students of European and non-European origin. The debate was situated within the pharmacy work placement and pharmacy practice II modules and attended by students and lecturers from these modules along with visiting international students and their lecturer. Students of the course are required to complete a 6-month work placement in a pharmacy. This component is known as their work placement module. The pharmacy practice II module includes instruction related to pharmacy law and the role(s) of technicians. The contemporary and expanding role of the pharmacy technician is also covered. The pharmacy work placement module delivers an introduction to the reflective blog assessment, used by students throughout their work placements. ${ }^{27}$ These modules are part of 


\section{American Journal of Pharmaceutical Education 2018; 82 (6) Article 6280.}

a comprehensive college course, which also includes modules in pharmacology, toxicology and therapeutics, health and safety, pharmaceutical formulations, microbiology, foundational chemistry, and nutrition.

Prior to developing the intervention, the pharmacy practice and work placement module lecturers met and set a time for the debate within both modules that would be ideal for students. They decided to hold the debate at the end of the pharmacy practice II module and immediately prior to the start of the pharmacy experiential work placement. This ensured that the students had been educated in the practice of pharmacy, their role and responsibilities within it, and that they had been introduced to the college code of conduct for students on work placement and that they would be trained in using blogs as a reflective assessment for placement. ${ }^{27}$

Several scenarios with ethical dimensions were written. Each of the scenarios allowed for a range of behavioral responses and provided an opportunity for students to exercise their reasoning skills. Although only three scenarios were used in the intervention, the remaining unused scenarios may be used in future debates (Appendix 1), allowing for year-to-year variability in the topics chosen.

Students were asked to complete 5-minute papers in class immediately before and after the debate. A "5-minute paper" is an in-class writing activity (taking 5 minutes or less to complete) in answer to an instructor-created question. ${ }^{28}$ The pre- and post-debate papers posed different ethical scenarios for students to consider and comment upon. They were designed to establish a baseline of a student's critical thinking and the impact of the debate on this thinking.

Following completion of the pre-debate 5-minute paper, students received a PowerPoint presentation (Microsoft, Redmond, WA) that provided the learning objectives of the exercise, a brief overview of ethics and ethical dilemmas, the difference between a moral and legal standard, codes of ethics for a profession, an outline of how the debate can help them approach the problem, and a definition of what a good debater embodies. A formal class debate was new to the students and the presentation was an important step in contextualizing the layout and objectives of the exercise.

Upon completion of the presentation, the debate scenario was posed and a modified think-pair-share strategy was adopted for the conduct of the debate. ${ }^{22}$ This strategy was adopted as the students were new to debating and it offered them a stepwise approach to formulating their positions. It eventually allowed the entire class to come together to share and challenge positions they have formulated about the case presented. Initially, in this format, students were given 10 minutes to plan and make notes individually on the debate scenario and then each student was randomly paired with another student. The pairs were given 10 minutes to share their ideas, combine their notes and think more deeply about the topic. On completion of this task, each pair outlined their thinking to the debate facilitators. Each unique strategy suggested was recorded on the board (five in all) and then groups of students (five students per group) were randomly assigned to argue for one of the strategies. The practice of using debates where the debaters must take the view or act out a role that is not necessarily their own is an effective way to teach ethics. ${ }^{29}$ Each group was given 15 minutes to prepare their case and then present to the class. Questions and class discussion were allowed at the end of each presentation. Facilitator involvement ensured strict timekeeping and avoided drifting off topic. An assessment rubric (Appendix 2) was developed and used to highlight to the students what was expected of a good debater. The rubric was also used to provide students with feedback on their performance following the debate.

A short round-up talk was given to guide students through issues raised and to give them useful reference sources. After the post-debate, students completed their 5minute papers and an anonymous online survey. In the subsequent afternoon session, students were asked to reflect on the debate as a way of exploring ethics and used this topic as their initial reflective blog entry. The visiting lecturer was given a questionnaire for later completion.

The next issue that arose was whether the students would be assessed on the intervention and if so, whether the marks assigned would contribute to their overall grade for the work placement module. It was decided that the debate would not influence students' grades. This was because the debate was an exploratory intervention designed primarily to assess its impact on students' ethical thinking skills not to grade them on their participation. The 5-minute papers were used only for analysis to determine any change in student learning. This methodology compares well with that of Stewart and colleagues' who used pre- and post-minute papers to measure the impact of an integrated assignment on their pharmacy course. The minute papers completed in that study before and after the assignment showed improvement in student learning. ${ }^{26}$

Survey completion was on a voluntary and anonymous basis. In relation to the students' reflective blog entries, they were requested to reflect on what they had learned from the debate. No marks were assigned to these entries. The study received approval from the Dublin Institute of Technology (DIT) ethics committee.

A constructivist ontological position was taken, which allowed for concepts about how ethics are perceived and developed by students to be produced through 


\section{American Journal of Pharmaceutical Education 2018; 82 (6) Article 6280.}

social dialogue and reflection. ${ }^{30}$ An interpretivist epistemological position was assumed because an interpretation of the students' reflection on ethical reasoning was required. This was appropriate because research into how each student perceives the outcome of an ethical dilemma must consider the differences in individuals, and the nature of an ethical dilemma by definition has no one correct outcome.

The methodology chosen for the study was an instrumental case study. ${ }^{31}$ This was appropriate because it was anticipated that the intervention would be easily adaptable more generally. A mixture of qualitative and quantitative methods was adopted; however, the focus was on qualitative analysis to support the interpretivist epistemology. Methods included analysis of before and after 5-minute papers, a sentiment survey, thematic analysis of student reflective writing, and a qualitative questionnaire by an independent observer. These are described in detail below:

Method 1: Before and after 5-minute papers. ${ }^{28,32}$ Students were asked to complete two 5-minute-paper exercises in class to measure the impact of the debate on their learning through the use of a paired $t$-test. The first was completed immediately prior to the debate. Students were presented with a scenario to consider and asked to write a 5-minute response outlining their thoughts on the scenario. The second paper was completed following the debate. Students were presented with a different scenario and asked to write a 5-minute response outlining their thoughts on the scenario. Papers were labelled by the students using their own unique identification code thereby allowing for anonymization but also pairing of the pre- and post-papers. Responses from the 5-minute papers were reviewed independently by the two participating lectures and ranked into 1 of 3 categories: the student comprehends the scenario's relevance and provides a developed exploration; the student somewhat comprehends the scenario's relevance and provides a semi-developed exploration; and the student does not comprehend the scenario's relevance and provides an undeveloped exploration. Each category was assigned a specific numerical score. A final ranking was applied to each 5-minute paper by calculating the average score from both lecturers. There was close agreement between the lecturers' numerical scores across all papers. Subsequent hypothesis testing and statistical $t$-testing were performed.

Method 2: After the debate, a short, follow-up online survey was administered to measure student opinions and sentiments toward the debate. ${ }^{33}$ Survey questionnaires were completed anonymously. Students were asked to rank their level of agreement with the following four statements using a 5-point Likert scale: the debate was an enjoyable experience; the scenario posed in the debate was interesting; following the debate, I have a better understanding of ethical dilemmas; and I found the thinkpair-share debate format informative. A short answer question sought students' opinion on the best aspect of the debate. Three yes/no questions were asked: Would you recommend that we use this method of teaching ethics again? Did you discuss or think about the debate issues over lunch? Did you discuss the use of the debate over lunch?

Method 3: The method chosen for the interpretation of the reflective assessments was through thematic analysis using a grounded approach that allowed themes to emerge, as opposed to seeking evidence to support specific themes. ${ }^{31}$ Independent double-blind coding of a random sample of assessments was performed.

Method 4: Independent observer questionnaire: At the time of the debate, a lecturer and students from Spain participated in the debate intervention activity. Their participation provided an international perspective to the debate with the Spanish students fully participating in the debate and their lecturer acting as an independent observer and completing a questionnaire following the debate. This questionnaire sought to garner the lecturer's opinion on: the effectiveness of the debate as a way to explore the topic of ethics with students, whether the predebate presentation was an appropriate introduction to the intervention, if the methodological approach used in the debate was suitable, if more guidance were to be provided where should it be focused, and whether the scenario presented in the debate allowed the students to develop their ethical reasoning skills.

\section{RESULTS}

Although 25 students participated in the debate, two were excluded because they arrived late for the pre-debate 5-minute paper, leaving the final number of paired 5-minute papers at 23. All final scores from the 5-minute papers were entered into Microsoft Excel (Redmond, WA) and comparisons between the pre- and post-debate papers were made using a paired $t$-test. Analysis of the 5-minute papers demonstrated a significant change $(p<.001)$ in students' ability to identify influencing ethical factors and potential courses of action between the pre- and post-debate (Appendix 3).

Following the debate, a short, follow-up online survey was administered to measure students' opinions regarding the debate. The results for the top four survey questions are shown in Figure 1 and the complete survey questions and results are shown in Table 1.

There were 25 blog entries. Students were asked to write a short reflective piece (about 500 words) on their experience with the academic debate and what they 


\section{American Journal of Pharmaceutical Education 2018; 82 (6) Article 6280.}

learned from it. Interpretation of data from the blogs was based on a thematic descriptive approach. From the entries, insights and awareness of student understanding and position on the debate could be drawn. Several key themes recurred across the multiple blogs, including surprise at the variety of different opinions expressed, acknowledgement of the importance of communication skills, appreciation of Codes of Ethics as useful reference sources, better understanding that different courses of action can have different consequences, recognition that personal feelings must not affect professional judgement, and recognition of the importance of behaving ethically during both their work placements and as they progress into their future careers.

Ninety-two percent of students made reference in the blogs about the ethical debate highlighting the significant difference of opinions that the class had on how to deal with the problem presented to them. The students reported that this led to them developing a deeper understanding of the need to be more analytical and critical before choosing a course of action. The next most common theme identified $(24 \%)$ was a reference to and/or acknowledgement of the importance of communication skills in dealing with ethical dilemmas. As emphasized by several students, ethical dilemmas can often relate to sensitive issues and good communication is key to dealing with them successfully. The following themes were also identified: an appreciation that Codes of Ethics are useful reference sources $(20 \%)$ and a better understanding that different courses of action can have different consequences (20\%). The final themes identified were recognition that personal feelings must not affect professional judgement (8\%) and

\section{STUDENT SURVEY}
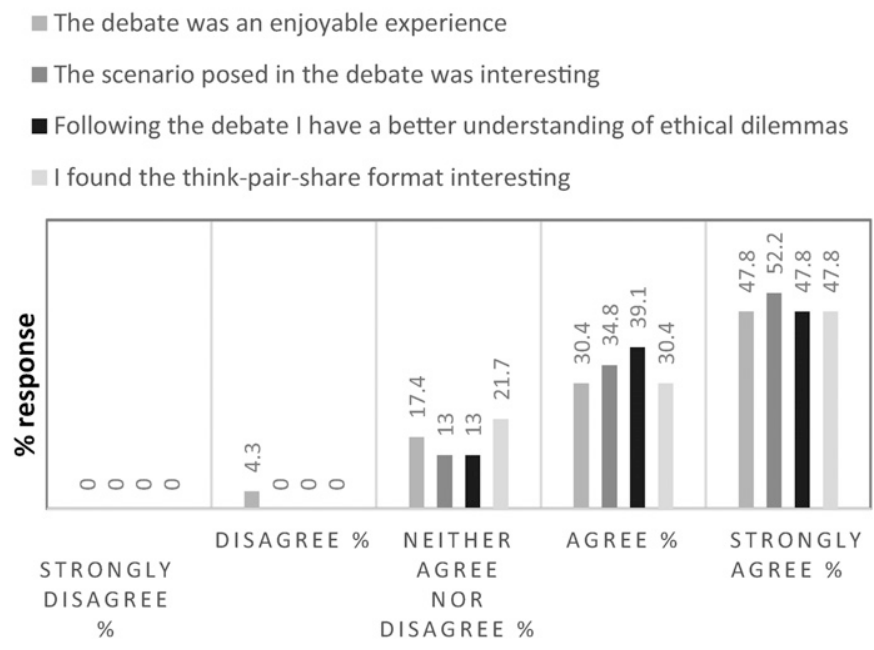

Figure 1. Top Four Survey Questions on Students' Opinions on Using Ethical Debate to Explore Ethics $(\mathrm{N}=23)$. recognition of the importance of behaving ethically during both their work placements and as they progress into their future careers (8\%). From the 25 student blog entries, four quotes are shown in Appendix 4.

The visiting lecturer reported that they felt there was no better way to explore ethics than an ethical debate. They reported that the pre-debate presentation was useful in delineating the difference between ethical and legal standards and for referencing ethical resources where pharmacy technicians are named. Using a rubric to outline the features of a good debate was considered helpful in demonstrating to students what is expected of them. The scenario presented in the debate was judged to be relevant and thought provoking in getting students to put forward an opinion that might not necessarily be their own, was an interesting exercise. The visiting lecturer mentioned that they would consider introducing an ethical debate into their own college course.

\section{DISCUSSION}

In this educational intervention, the study authors set out to evaluate the effectiveness of a debate on an ethical dilemma on the development of ethical reasoning skills in pharmacy technician students.

Some students initially expressed anxiety about participating in the debate. Five-minute papers and formal debates were new experiences for many of them and outside their usual classroom experience of traditional didactic instructional methods and separate subject approaches. That such methods and approaches exist is not unique to this course. Guile and Ahamed reported on modernizing the pharmacy curriculum and reported that students said that "they were not able to link their academic training together because the different subjects were taught in 'silos' and without cross-referencing in either teaching or assessment."

Once the pre-debate presentation was given and the rationale for the intervention and the assessment strategy explained, $78 \%$ of the students said that they agreed or strongly agreed that the debate was enjoyable and $87 \%$ agreed or strongly agreed that the scenario posed in the debate was interesting. All of the students said the debate was a good way of introducing ethics and that it should be included in the course. This resonates well with Kennedy's statement that "in-class debates provide fertile ground for active learning and the cultivation of critical thinking and oral communication skills." 22

The debate has also prompted discussion among the course team members regarding the possibility of using this type of approach to address other issues on the curriculum that need attention. Hanna and colleagues reported that debates offer a useful strategy for teaching ethics in pharmacy courses. ${ }^{3}$ They report that in their 
American Journal of Pharmaceutical Education 2018; 82 (6) Article 6280.

Table 1. Pharmacy Technician Students' Opinions on Using Ethical Debate to Explore Ethics $(N=23)$

\begin{tabular}{|c|c|c|c|c|c|}
\hline Question & $\begin{array}{c}\text { Strongly } \\
\text { Agree ( \%) }\end{array}$ & Agree ( \%) & $\begin{array}{c}\text { Neither Agree } \\
\text { nor Disagree (\%) }\end{array}$ & Disagree (\%) & $\begin{array}{l}\text { Strongly } \\
\text { Disagree }\end{array}$ \\
\hline The debate was an enjoyable experience. & 7.8 & 30.4 & 17.4 & 4.3 & 0 \\
\hline The scenario posed in the debate was interesting. & 52.2 & 34.8 & 13.0 & 8.0 & 0 \\
\hline $\begin{array}{l}\text { Following the debate, I have a better understanding } \\
\text { of ethical dilemmas. }\end{array}$ & 47.8 & 39.1 & 13.0 & 0 & 0 \\
\hline I found the think-pair-share format interesting. & 47.8 & 30.4 & 21.7 & 0 & 0 \\
\hline
\end{tabular}

study, using a series of debate workshops effectively delivered course content on ethical issues and that $70 \%$ of their students strongly agreed or agreed that debates were a useful teaching method in the Master of Pharmacy (MPharm) program. ${ }^{3}$

Eighty-seven percent of the students reported that they had a better understanding of ethics following the debate. Their reflective blog entries also indicated that they had developed an appreciation of the complexity of

Table 2. Pharmacy Technician Students' Answers to the Question: "What Was the Best Aspect of the Debate?'

Everyone enjoyed it. If you could make the ethical question more health care-y stealing is really broad. Like maybe your friend starts going out with someone that you know from your pharmacy is HIV+ or something.

The interaction with my peers as a whole group.

Learning what to do in the future in my pharmacy, if put in a similar situation.

It opened my eyes to other people's opinions.

Discussing the different approaches that could be taken for a situation.

Seeing how fellow students would handle work-related situations.

What the best approach would be.

You heard all aspects of the debate.

Different opinions on how to act or react in a tricky situation in the work place.

Working with other team mates getting their opinion.

Discussing with others in the class about how they would approach the situation and realising there is no easy answer.

Groups discussing it.

Sharing opinions as a group.

Discussion on different opinions.

Learning about different approaches to the given scenario.

Hearing everyone's opinion.

Seeing different opinions.

Sharing opinions.

Hearing everyone's different opinions.

Having my eyes opened to many different situations. There's not always one right answer.

Problem solving.

Seeing all the different opinions. many ethical issues. For example, they had to consider the scenario presented to them at the start of the debate, synthesize their individual response, discuss their response with a peer, present an agreed response and then put forward an assigned response in the debate that was not necessarily their own. This approach helped them understand the need to take an analytical and considered approach to ethical matters and to appreciate the importance of communication skills, such as speaking and listening when resolving ethical dilemmas in the workplace.

The role of debate in improving critical thinking and communication skills and ability to analyze and evaluate evidence was also found. This is evidenced by the improved performance between the pre- and post-debate 5 -minute papers and in the high percentage $(87 \%)$ of students who reported that they felt they had a better understanding of ethical dilemmas following the intervention. These results compare favorably with a controlled "before and after" study by Strawbridge and colleagues involving physiotherapy and pharmacy students on an interprofessional education (IPE) debate on ethics and professionalism. The students in that study agreed that debating ethics through IPE was a valid teaching modality. They found the debates challenging and stimulated critical thinking and interest in complex and controversial issues. The students also found it beneficial to work as a team. The researchers concluded that in-class debate is a useful way of learning together. ${ }^{35}$ This latter sentiment was also reflected in the student blogs and surveys.

Lin and Crawford reported that a novel online-debate forum was a feasible teaching and learning strategy,

Table 3. Survey Questions

\begin{tabular}{lcc}
\hline & Yes & No \\
\hline $\begin{array}{l}\text { Would you recommend that we use this } \\
\text { method of teaching ethics again? }\end{array}$ & 100 & \\
$\begin{array}{l}\text { Did you discuss or think about the debate } \\
\text { issue over lunch? }\end{array}$ & 71.4 & 28.6 \\
$\begin{array}{l}\text { Did you discuss the use of the debate over } \\
\text { lunch? }\end{array}$ & 56.5 & 43.5 \\
\end{tabular}




\section{American Journal of Pharmaceutical Education 2018; 82 (6) Article 6280.}

which helped pharmacy students improve their communication skills and critical thinking, expanded their scope of knowledge, and provided a platform for group process. ${ }^{36}$ Further confirmation of the positive impact the debate had on increasing student knowledge and understanding of ethics was demonstrated in the results of the paired $t$ test $(p<.001)$. In the context of the competencies delineated in the professional development of pharmacy technicians, ethical, legal and professional responsibilities loom large.

This study is limited by a small sample size. However, as there was a high participation rate in the activities, the latter factor is not considered fundamental to the outcome of the study. This is because $100 \%$ of students participated in the debate and wrote a reflective blog entry, $92 \%$ completed the pre- and post-debate 5-minute papers, and $92 \%$ completed the student sentiment survey. The results of this study show a positive impact on student learning and with further research and larger sample sizes could be generalizable to educators who teach pharmacy technicians. There is some corroboration of this by the fact that the visiting lecturer opined that they would consider introducing an ethical debate into their course.

Finally, based on the results of the 5-minute papers and the opinions and perceptions indicated in the surveys and reflective blogs, the debate was deemed a successful way to integrate ethics into the pharmacy technicians course. The study authors propose for it to be an integral component of the newly implemented professional development ePortfolio module and be assessed through this module going forward. In terms of future directions for the assignment, the study authors propose that the rubric designed for debating skills feedback be used for grading purposes, and for future sentiment surveys, the students be asked for suggestions on how the exercise could be improved.

\section{CONCLUSION}

A debate on an ethical dilemma was an effective method to integrate ethics into the professional formation of pharmacy technicians. It had a positive impact on the participants' ethical reasoning skills and their beliefs pertaining to the importance of ethics in pharmacy practice. Additionally, it demonstrated the benefits of working in a group to discuss important issues.

\section{REFERENCES}

1. Hall D. Debate: innovative teaching to enhance critical thinking and communication skills in health care professionals. Internet $J$ Allied Health Sci Pract. 2011;9(3):Article 7.

2. Darby M. Debate: A teaching-learning strategy for developing competence in communication and critical thinking. J Dent Hyg. 2007;81(4):Article 78.
3. Hanna L, Barry J, Donnelly R, et al. Using debate to teach pharmacy students about ethical issues. Am J Pharm Educ. 2014; 78(3):Article 57.

4. The Pharmacy Act 2007. http://www.irishstatutebook.ie/2007/ en/act/pub/0020/index.html. Accessed April 12, 2017.

5. Hogan S. The education, training, workplace learning and regulation of non-pharmacist pharmacy staff: current approaches in the Republic of Ireland. University of Sheffield, Sheffield. http://etheses.whiterose.ac.uk/7289/.

6. Accreditation Council for Pharmacy Education. The professionwide dialogue concerning the development of national standards and an accreditation process for pharmacy technician education and training. 2003. http://www.pharmacycredentialing.org/files/ techcomments.pdf. Accessed April 10, 2017.

7. Accreditation Council for Pharmacy Education. Accreditation Standards for Pharmacy Technician Education and Training Programs. 2016. https://www.acpe-accredit.org/pdf/ Standards2016FINAL.pdf. Accessed June 142018.

8. Debate: pharmacy technicians time for a change? Irish Pharmacy News. 2013;12(8):14-15.

9. NAHPT Annual Report. 2011. www.pharmtech.ie/. Accessed April 10, 2017.

10. The Pharmacy Order 2010. https://www.legislation.gov.uk/ ukdsi/2010/9780111487358/contents. Accessed April 10, 2017.

11. Oxford English Dictionary (2017). https://en.oxforddictionaries. com/definition/ethics. Accessed April 11, 2017.

12. Hattab AS. Current trends in teaching ethics of healthcare practices. Dev World Bioeth. 2004;4(2):160-172.

13. Hindmarch T, Allikmets S, Knights F. A narrative review of undergraduate peer-based healthcare ethics teaching. Int J Med Educ. 2015;6:184-190.

14. Gray A. Codes of ethics should be developed across health care professions, says FIP. Pharm J. 2014;293(7828).

15. FIP statement of professional standards codes of ethics for pharmacists. 2014. http://apps.who.int/medicinedocs/en/d/

Js19757en/. Accessed April 8, 2017.

16. American Association of Pharmacy Technicians. Code of ethics for pharmacy technicians. https://www.pharmacytechnician.com/ code-of-ethics/. Accessed April 8, 2017.

17. General Pharmaceutical Council of Great Britain standards of conduct, ethics and performance. 2012. https://www.patientlibrary. net/tempgen/849.pdf. Accessed April 8, 2017.

18. Pharmacy Technician Certification Board. Code of conduct. https:// www.ptcb.org/resources/code-of-conduct\#. Accessed April 8, 2017.

19. General Pharmaceutical Council. Standards for pharmacy professionals. https://www.pharmacyregulation.org/standards. Accessed June 14, 2018.

20. Professional competencies for Canadian pharmacy technicians. http://napra.ca/pharmacy-technicians/professional-competenciescanadian-pharmacy-technicians-entry-practice. Accessed June 14, 2018.

21. Sher S. Suggestions for incorporating lessons on ethics into your course. University of Southern California, College of Letters, Arts and Sciences. http://dornsife.usc.edu/levan-institute/ethics-in-theclassroom/. Accessed April 8, 2017.

22. Kennedy R. In-class debates: fertile ground for active learning and the cultivation of critical thinking and oral communication skills. Int J Teach Learn High Educ. 2007;19(2):183-190.

23. Lampkin SJ, Collins C, Danison R, Lewis M. Active learning through a debate series in a first-year pharmacy self-care course. $\mathrm{Am} J$ Pharm Educ. 2015;79(2):Article 25. 


\section{American Journal of Pharmaceutical Education 2018; 82 (6) Article 6280.}

24. Randolph SD. Student perceptions of the use of debate as a teaching strategy in the allied health professions. $J$ Allied Health. 2007;36(1):e13-e29.

25. Rubin RW, Weyant RJ, Trovato CA. Utilizing debates as an instructional tool for dental students. J Dent Educ. 2008;72(3):282-287. 26. Stewart AL, Buckner IS, Wildfong PL. A shared assignment to integrate pharmaceutics and pharmacy practice course concepts. $\mathrm{Am}$ $J$ Pharm Educ. 2011;75(3):Article 44.

27. Dunne J, Ryan SM. Enhancing professional development and supporting students on work placement through peer-peer learning using an online blog assessment. Irish J Acad Pract. 2016;5(1):1-25. 28. Angelo T, Cross P. Classroom Assessment Techniques: A Handbook for College Teachers. 2nd ed. San Francisco, CA: Jossey-Bass; 1993. 29. Balogh DW. Teaching ethics across the psychology curriculum. Association for Psychological Science. 2002. http://www.

psychologicalscience.org/observer/0902/tips.cfm. Accessed April 10, 2017.

30. Cousin G. Researching Learning in Higher Education : An Introduction to Contemporary Methods and Approaches. London, UK: Routledge; 2009.
31. Cohen L, Manion L, Morrison K. Research Methods in Education. 6th ed. London, UK, New York, NY: Routledge; 2007.

32. Singh M, Lawrence R, Headrick L. Expanding educators' medical curriculum tool chest: minute papers as an underutilised option for obtaining immediate feedback. J Grad Med Educ. 2011; 3(2):239-242.

33. Kelley K, Clark B, Brown V, Sitzia J. Good practice in the conduct and reporting of survey research. Int J Qual Health Care. 2003;15(3):261-266.

34. Guile D, Ahamed F. Modernising the Pharmacy Curriculum. 2011. http://www.llakes.ac.uk/sites/default/files/26.\%20Guile $\% 20 \%$ 26\%20Ahamed\%20-\%20final.pdf. Accessed April 8, 2017.

35. Strawbridge JD, Barrett AM, Barlow JW. Interprofessional ethics and professionalism debates: findings from a study involving physiotherapy and pharmacy students. J Interprof Care. 2014; 28(1):64-65.

36. Lin SJ, Crawford SY. An online debate series for first-year pharmacy students. Am J Pharm Educ. 2007;71(1):

Article 12. 


\section{American Journal of Pharmaceutical Education 2018; 82 (6) Article 6280.}

Appendix 1. Synopsis of Pre-debate Scenario, Debate Scenario and Post-debate Scenario

\section{Five-minute pre-debate scenario}

You overhear what you feel is an inappropriate conversation between two staff members in the locker room of a small community hospital.

\section{Debate Scenario}

You have reason to suspect a high-ranking staff member, which you have been having personal difficulties with of stealing medication from the dispensary.

\section{Five-minute post-debate scenario}

You work in a pharmacy which is under increasing commercial pressure and you notice a short-dated product at the time of dispensing.

Appendix 2. Assessment Rubric for Debating Skills Feedback

\begin{tabular}{|c|c|c|c|c|c|}
\hline & $\begin{array}{c}\text { Level of } \\
\text { Performance }\end{array}$ & $\begin{array}{c}\text { Level of } \\
\text { Performance }\end{array}$ & $\begin{array}{c}\text { Level of } \\
\text { Performance }\end{array}$ & $\begin{array}{c}\text { Level of } \\
\text { Performance }\end{array}$ & Total \\
\hline Category & 4 & 3 & 2 & 1 & \\
\hline $\begin{array}{l}\text { Supports with examples and } \\
\text { facts (examples and facts } \\
\text { are given to support } \\
\text { reasons) }\end{array}$ & $\begin{array}{l}\text { Uses many facts that } \\
\text { support topic }\end{array}$ & $\begin{array}{l}\text { Uses some facts that } \\
\text { support topic }\end{array}$ & $\begin{array}{l}\text { Uses few facts that } \\
\text { support topic }\end{array}$ & $\begin{array}{l}\text { Does not use facts } \\
\text { that support topic }\end{array}$ & \\
\hline $\begin{array}{l}\text { Persuasiveness (convinces } \\
\text { audience to their point of } \\
\text { view) }\end{array}$ & $\begin{array}{l}\text { Arguments clear and } \\
\text { convincing }\end{array}$ & $\begin{array}{l}\text { Arguments are } \\
\text { sometimes clear } \\
\text { and convincing }\end{array}$ & $\begin{array}{l}\text { Arguments are rarely } \\
\text { clear and } \\
\text { convincing }\end{array}$ & $\begin{array}{l}\text { Arguments are never } \\
\text { clear and } \\
\text { convincing }\end{array}$ & \\
\hline $\begin{array}{l}\text { Presentation style/rebuttal } \\
\text { (tone of voice, use of } \\
\text { gestures, and level of } \\
\text { enthusiasm are convincing } \\
\text { to audience/arguments } \\
\text { made by the other teams } \\
\text { are responded to and dealt } \\
\text { with effectively) }\end{array}$ & $\begin{array}{l}\text { All style features were } \\
\text { used convincingly/ } \\
\text { Many effective } \\
\text { counter-arguments } \\
\text { made }\end{array}$ & $\begin{array}{l}\text { All style features } \\
\text { were used most } \\
\text { convincingly/ } \\
\text { Some effective } \\
\text { counter-arguments } \\
\text { made }\end{array}$ & $\begin{array}{l}\text { Few style features } \\
\text { were used } \\
\text { convincingly/Few } \\
\text { effective counter- } \\
\text { arguments made }\end{array}$ & $\begin{array}{l}\text { Few style features } \\
\text { were used; not } \\
\text { convincingly No } \\
\text { effective counter- } \\
\text { arguments made }\end{array}$ & \\
\hline
\end{tabular}


American Journal of Pharmaceutical Education 2018; 82 (6) Article 6280.

Appendix 3. Data from the Pre- and Post-debate 5-Minute Papers (N=23)

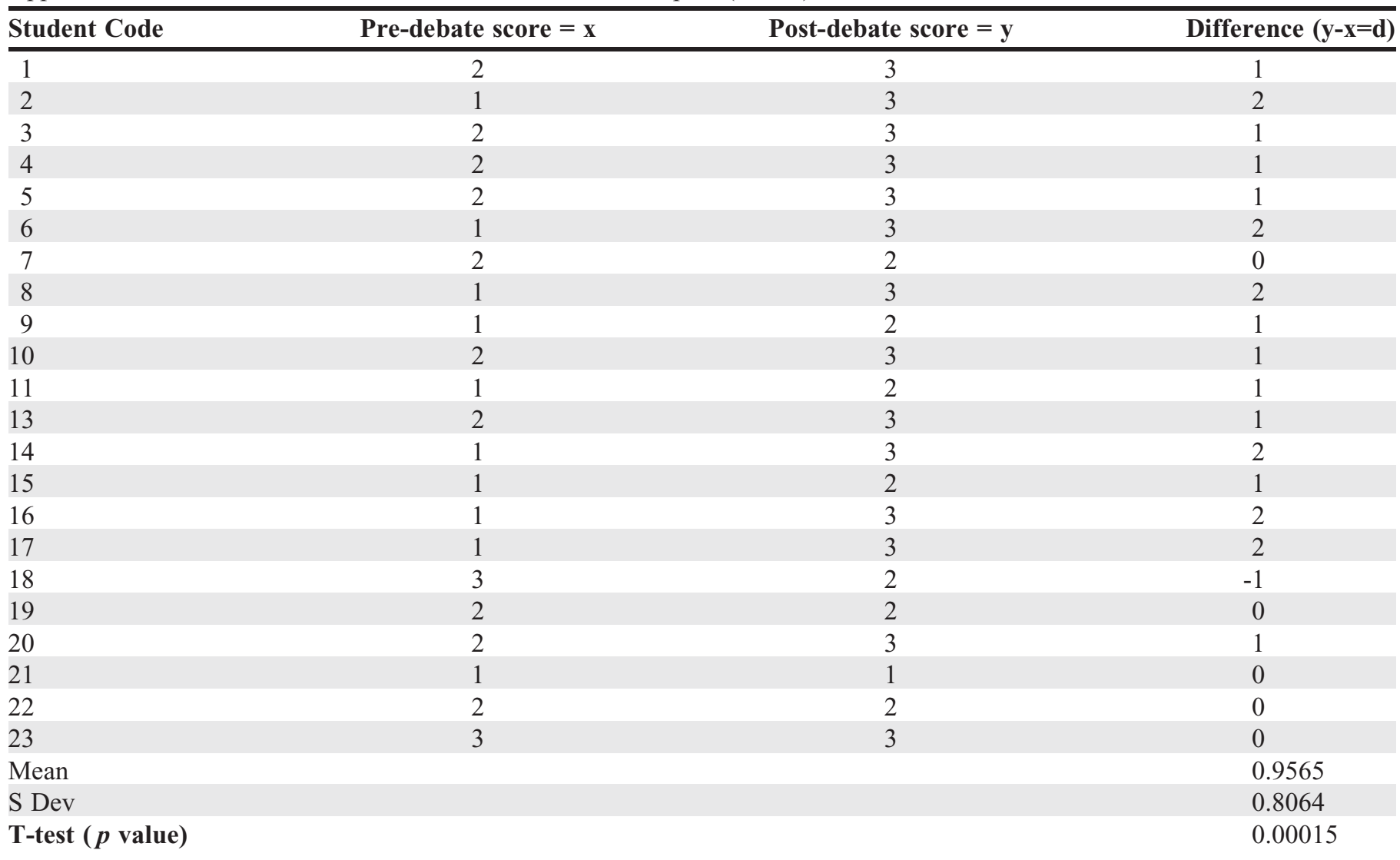

Appendix 4. A Selection of Student Quotations from their Blog Entries

From the debate, I have learned that many different actions could be taken for any given situation. All these different actions have different outcomes and consequences.

On reflection and listening to other people's arguments, I learnt that there are other ways to approach this situation.

During today's class of the ethical debate, I learnt how important it is to look at every aspect of a scenario or situation before making an informed decision on what to do. My learning experience included thinking about things critically and reflecting on how particular decisions may impact the outcome of a situation. Working in groups to debate scenarios of situations we didn't necessarily agree with enabled me to think outside the box and learn from my peers. This was beneficial as I had to stand up and speak to my class and be convincing about a situation I wasn't passionate about, which I found quite difficult. Teasing out different options of how to handle difficult and often sensitive situations enabled me to think about the importance of communication within the workplace, confidentiality and what it is to be ethical and morally correct.

The activity that took place this morning encouraged me to link the code of ethics we need to read before work placement to real-life situations. 